\title{
Modular Strategies: B2B TECHNOLOGY AND ARCHITECTURAL KNOWLEDGE
}

\author{
Pierre J. Richard \\ Timothy M. Devinney
}

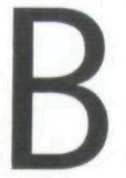

usiness-to-business information technology systems (B2B technologies) seek to create value for customers by intensifying market competition, providing information to coordinate the supply chain, and leveraging capabilities across organizations. Business journalism has claimed again and again that these technology-enabled systems have the potential to alter the face of modern industrial activity. ${ }^{1}$ Building upon the concept of modularity, ${ }^{2}$ this article makes a qualitative assessment of the capacity of B2B technologies to recast supply chains.

The plethora of B2B technologies makes developing a comprehensive categorization difficult. Most B2B initiatives are somewhat erroneously labeled as "exchanges," even though they encompass many distinct forms-from e-marketplaces that match buyers and sellers, to private vertical exchanges that facilitate just-in-time manufacturing through information sharing. Once one appreciates that the goal of these initiatives can be represented as seeking efficiency in asset utilization and enhancing the innovative use and creation of new asset structures-which are traditionally discussed as "Ricardian" and "Schumpeterian" rents-a simple framework can characterize these diverse initiatives.

B2B technologies can be used to pursue differing modular strategies. Two generic B2B strategies are: "modularization," which allows a firm to rent out its internal capabilities to others in its industry; and "architectural entrepreneurship" that alters how the supply chain is arranged by allowing a central 
coordinating firm to overcome problems associated with trust and information asymmetry. These strategies provide significant opportunities for the generation of extra economic rents by leveraging capabilities across multiple supply chains (Ricardian) and designing improved supply chain systems (Schumpeterian).

In order to decompose these strategies and develop a general framework, we investigated several archetypal organizations: Cemex, Li \& Fung, Eastman Chemical, Agribuys, and Dell. Together these firms cover a diverse range of industries from building materials to apparel, groceries, and computers and represent both established firms and a start-up (Agribuys). Our findings place architectural knowledge-that is, knowledge of how the different activities in the supply chain interact-at the center of B2B-driven change. Our research suggests three managerial implications:

- Prescription 1: Only firms with extensive architectural knowledge can achieve the higher-order collaborative benefits of B2B supply chain technologies. Firms lacking extensive knowledge are limited to smaller efficiency-driven benefits. Learning and codification are central to building and harnessing the required architectural knowledge.

- Prescription 2: The form that collaborative B2B initiatives take depends on the indispensability of the focal firm in the supply chain. Indispensable firms, such as those undertaking capital-intensive activities, should adopt technologies that radiate outwards, offering their capabilities to a wider market. We describe such a strategy as modularization. Dispensable firms should use technology to draw together new combinations of firms, to create new supply chains. This strategy is one of architectural

Pierre Richard is an Associate Lecturer in the School of Economics at the University of New South Wales and a Doctoral Candidate at the Australian Graduate School of Management.

Timothy M. Devinney is Professor of Management and Director of the Centre for Corporate Change at the Australian Graduate School of Management. entrepreneurship.

- Prescription 3: Over time, industry evolution puts pressure on rents earned from asset utilization. To continue to earn rents, firms must increasingly turn towards the Schumpeterian rents that can be earned from creating new supply chain structures. This suggests that building architectural knowledge should be a key strategic activity.

\section{B2B Technology}

Firms are being offered a proliferation of information technology systems that address their interactions with supply chain participants. Recent interest has focused on B2B "exchanges." B2B exchanges are sites hosted on electronic networks that perform business functions. The common element of these functions is that they involve interaction between two or more participants, though these may be firms or the divisions of a single firm. Features of B2B exchanges include establishing electronic markets and auctions (matching buyers and sellers), 
TABLE I. B2B Initiatives (Modal Combinations)

\begin{tabular}{|c|c|c|c|}
\hline $\begin{array}{l}\text { Exchange } \\
\text { Attributes }\end{array}$ & $\begin{array}{l}\text { Private Vertical } \\
\text { Exchanges }\end{array}$ & $\begin{array}{l}\text { Independent } \\
\text { e-Marketplaces }\end{array}$ & Industry Consortia \\
\hline Users & One-to-Many & Many-to-Many & Some-to-Many \\
\hline Ownership & $\begin{array}{l}\text { Focal Firm } \\
\text { (the "one" above) }\end{array}$ & $\begin{array}{l}\text { Independent Intermediary } \\
\text { (distributor or start-up) }\end{array}$ & $\begin{array}{l}\text { Founding Firms } \\
\text { (the "some" above) }\end{array}$ \\
\hline $\begin{array}{l}\text { Owner } \\
\text { Transaction } \\
\text { Participation }\end{array}$ & Yes & No & $\begin{array}{l}\text { No, owners transact } \\
\text { separately on their own } \\
\text { behalf }\end{array}$ \\
\hline \multirow[t]{3}{*}{ Focus } & Vertical (single industry) & $\begin{array}{l}\text { (a) Horizontal (indirect goods } \\
\text { across sectors), or }\end{array}$ & Vertical \\
\hline & & (b) Vertical, or & \\
\hline & & $\begin{array}{l}\text { (c) Niche (single product, } \\
\text { service or process) }\end{array}$ & \\
\hline Functionality & $\begin{array}{l}\text { High-all including } \\
\text { collaboration }\end{array}$ & $\begin{array}{l}\text { Varied-trading and services, } \\
\text { very little collaboration }\end{array}$ & $\begin{array}{l}\text { Medium-most services, } \\
\text { some collaboration }\end{array}$ \\
\hline $\begin{array}{l}\text { Other } \\
\text { Features }\end{array}$ & $\begin{array}{l}\text { Generally customizable } \\
\text { to users' needs, limited to } \\
\text { current trading partners }\end{array}$ & $\begin{array}{l}\text { Intermediary is unbiased, also } \\
\text { open to all potential } \\
\text { participants }\end{array}$ & $\begin{array}{l}\text { Participants include } \\
\text { partners of owners plus } \\
\text { scope for additional users }\end{array}$ \\
\hline
\end{tabular}

providing back-end services (such as order processing), providing business tools (such as design and planning support services) and enabling supply chain "collaboration." In general, the benefits of B2B exchange initiatives are increased information sharing, gaining the capacity to serve new segments of the market profitably, and dynamic pricing that identifies low-cost suppliers more effectively. ${ }^{3}$ B2B exchanges follow on from earlier supply chain initiatives. For instance, just-in-time inventory management has sought to optimize production by coordinating activities across the supply chain. Similarly, the continuous replenishment system pioneered by Procter \& Gamble in the early 1990s improved supply chain operation by linking point-of-sale scanner panel data directly to manufacturers. This enabled Procter \& Gamble to anticipate and accommodate demand fluctuations more effectively. ${ }^{4}$ Increasingly, these supply chain initiatives are also being deployed in the form of "exchanges" although they differ significantly from the e-marketplaces that originally typified B2B exchange initiatives. Consistent with this terminology we will use "B2B exchange" and "B2B technology" interchangeably.

There are a number of exchange models currently being pursued (see Table 1 for a summary). They differ in their user concentrations, ownership, focus, and functionality. These elements can be combined in many ways, ${ }^{5}$ but there are certainly dominant modalities. To illustrate the range of offerings, we examine the following three common exchange types: 
- Private Vertical Exchanges - sites set up by large organizations to provide a wide range of services to their existing suppliers and customers. Successful examples include sites run by Wal-Mart, Dell, Cisco, and Cemex.

- Independent e-Marketplaces - exchanges offering tools and coordination to support user transactions. FreeMarkets is the most noted example of an independent exchange. ${ }^{6}$

- Industry Consortia - exchanges jointly established by leading companies within an industry. The classic example is Covisint, an exchange founded by GM, Ford, Renault-Nissan, and DaimlerChrysler as a joint venture (www.covisint.com). Covisint facilitates trade between its member firms and their existing suppliers. It is also important to note that although the owners of the exchange do transact on these networks, they do so independently of the consortia's own activities. Consortia do not trade on their own behalf, but merely oversee transactions and provide the infrastructure to execute them.

\section{Modular Systems and Architectural Knowledge}

As noted, B2B technology can have a significant impact on firm boundaries and the structure of the supply chain. However, despite much hype, there has been relatively little research attempting to explain the changes being observed. One notable exception is the application of transaction cost perspectives. ${ }^{7}$ Transaction cost theory places primary emphasis on asset specificity, which determines the relative benefits of vertically integrated structures or market coordination. However, changes in asset specificity are often attributed to technology, which is itself exogenous to transaction cost theory. To gain a better understanding of the competitive impact of B2B technology, we examine the role of knowledge in driving B2B initiatives and draw on the wide-reaching concepts of architectural knowledge and modular systems. These concepts allow us to link technological change to the structure of the supply chain. This is because the "loose coupling" at the center of modular systems is defined according to knowledge flows, ${ }^{8}$ the same flows that determine technological change. Indeed, modularity has been invoked extensively in research on product innovation, but has been expanded to cover economic activity in general; that is, organizational forms themselves. ${ }^{9}$ This makes a modular perspective particularly powerful in explaining B2B initiatives, as it provides a deeper appreciation of the technology-driven dynamics involved in the evolution of the supply chain. Moreover, by linking firm boundaries to innovation, we provide firms with insight into how they should respond to the challenges posed by supply chain competition.

\section{Modular Systems}

Modularity is based on a systems theory view of organizations and their processes. It seeks to investigate how a system's components are "coupled" together and how tight these bonds are. ${ }^{10}$ Increased modularity enables the parts 
of a system to be separated and combined with much greater flexibility. ${ }^{11}$ Baldwin and Clark have attributed this added flexibility to two closely related effects: one from splitting components and the other from the substitutability between them. ${ }^{12}$ By splitting systems up, designers can partially modify components that were previously treated as a single unitary activity by altering individual modules (that is, smaller parts of the system). This opens up new, potentially beneficial, combinations of attributes by significantly reducing the cost of making alterations. Substitutability takes this further because participants can evaluate and alter each module separately without having to evaluate the entire system in a holistic way. This enables them to test many more variations of each component and thereby improve the overall design. Therefore, design flexibility adds value by making it possible to develop a greater number of components (through splitting design) and evaluate more combinations of them (through substitutability).

Under traditional arrangements, supply chains are composed of firms and markets. Activities with extensive interdependencies are placed inside a single firm, to ensure that these aspects are coordinated effectively and not subject to the hazards of opportunism. ${ }^{13}$ These firms are linked by markets that enable the efficient coordination of activities through the price mechanism. Modular approaches start by putting in place standardized component interfaces to coordinate activities. These interfaces define the functional and spatial relationships between modules. This allows each module to operate independently of the others, as long as they all conform to the standardized interface requirements that ensure that the system is synchronized. Activities can then be distributed between several parties, because coordination is embedded in the standardized interfaces and occurs automatically. Further, other alternate modules may be easily substituted and integrated into the loosely coupled chain as long as they too meet the requirements of the interface.

A modular system has three generic elements. First, there are the modules, the discrete functional activities that work on inputs to create distinct outputs. ${ }^{14}$ Then there are the interfaces. These set out strict requirements that the inputs and outputs of each module must adhere to. In doing so, they standardize the boundaries of the modules. This standardization allows any module to become part of the system, irrespective of its internal arrangement or operation as long as it fulfils the interface requirements. ${ }^{15}$ Finally, there are the interactions that pass over the interfaces, including communication or the exchange of material goods. Figure 1 illustrates how these are arranged.

These three elements can be considered from two perspectives: one physical and the other informational. On the physical level, a modular system manifests itself in the form of technology, including hardware such as computers and cables as well as the code that makes it operate. We term the physical technology of a system the "infrastructure." On the informational level, a modular system is defined by the knowledge that sets out how the technology is arranged. This informational aspect of a system is its "superstructure." Although the operation of the superstructure is reliant on the infrastructure that supports it, the nature of these two aspects is independent. For instance, the superstructure that 
FIGURE I. The Elements of a Modular System

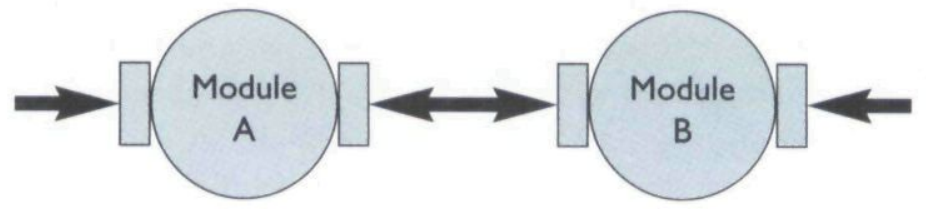

Key: Interface $[\quad$ Module $\bigcirc$ Interaction

sets out what a purchase order needs to achieve can be implemented using several different technological alternatives including EDI, facsimile, e-mail, and post.

\section{Architectural Knowledge}

The role of knowledge in facilitating the division of a supply chain into its modular components is clarified by considering the distinction between different types of product knowledge and innovation. The terms "incremental" and "radical" categorized innovation by its effects on a product, contrasting innovation that improves on an existing design and maintained the existing market structures with innovation that fundamentally reshapes market and product characteristics. Henderson and Clark's influential work suggests a more discerning approach by defining the two forms of knowledge that firms use as "architectural" and "modular." 16 Architectural knowledge is knowledge about the linkages between components: it says how components relate to each other. This architectural knowledge constitutes the superstructure embodied within the modular system. Modular knowledge covers the content of components: their individual characteristics and functions. To avoid confusion, we will refer to this "modular" knowledge as component knowledge. Innovation that covers the arrangement of components is termed "architectural" innovation, while that impacting the content of the components only is called "modular" innovation. "Radical" innovation can then be seen as innovation that alters both components and the linkages between them, while "incremental" innovation is much more evolutionary; neither the architecture nor modules are changed significantly, confirming existing arrangements.

\section{Supply Chains as Knowledge Structures}

The concept of architectural knowledge and the flexible "loose coupling" provided by modular systems combine to build a picture of supply chains as embedded knowledge structures. Traditionally, architectural knowledge has been embedded in the organizational structure of firms and the arrangement of supply chains. This is because architectural knowledge sets out how tasks are to be 
distributed, what communication is necessary between participants, and even the heuristics that employees use. ${ }^{17}$ Over time, all these elements become entrenched in organizations and their routines, such that the knowledge becomes implicit in structures and processes. Modularity provides firms with an alternate way to coordinate activities. Essentially, instituting a modular system takes the architectural knowledge embedded in an organizational arrangement and decomposes it to create an assortment of smaller units connected by standardized interfaces. This enables firms to manage their architectures explicitly because they are able to perceive what requirements are built into their interfaces and to consciously address them, independently of component knowledge. Indeed, modularity allows firms to break out activities from their supply chains based on the characteristics of the knowledge flows inherent in the activity. In this way, the establishment of standardized interfaces traces the boundaries of effective vertical and horizontal integration.

Modular control over architectural knowledge provides important benefits over traditional embedded architectures. Not only can the architecture be altered, but also firms can distribute tasks in new ways as the interfaces ensure effective communication and coordination. This offers the potential to add new components that draw on knowledge held outside the firm and also to improve quality by sourcing from specialist firms with deeper component knowledge. Moreover, the ability to manipulate architectural knowledge allows firms to isolate, and respond to, architectural innovation far more easily. A classic example of the strategic salience of architectural knowledge is the failure of British and U.S. motorcycle manufacturers to mount a credible defense against Honda's entry into their markets during the 1980s. Honda's entry displaced these incumbents, driving them into small niche markets or out of business. However, it is clear that the incumbent manufacturers possessed considerable knowledge, as they had been active in the industry for a long time. This makes it unlikely that it was Honda's competence in engine design per se that undermined them. ${ }^{18}$ Rather, they were unable to respond due to the inaccessibility of their embedded architectural knowledge. Organizationally, their systems could not even comprehend the innovation of small bikes, let alone respond effectively. Some commentators argue that the splitting of component and architectural innovation leads to synergies being lost because it reduces the flow of knowledge between these two activities. ${ }^{19}$ Nevertheless, in comparing setting interfaces at the outset (the modular approach) against accepting whatever structures occur naturally (the traditional approach), modularity at least allows managerial choice rather than environmental chance to determine the arrangement.

The relationship between architectural knowledge and modularity suggests that firms must possess sufficient architectural knowledge and be able to access this in an explicit form in order to adopt modular approaches. Architectural knowledge is generated by the learning that supports the evolution of organizational routines. This learning is a function of search processes whereby firms test new routines, and retain improved approaches. ${ }^{20}$ This incremental improvement has been described as "experience accumulation." ${ }^{21}$ As noted, the architectural knowledge generated in this manner is tacit, embedded in routines 
TABLE 2. Benefits of $B 2 B$ "Exchange" Initiatives

\begin{tabular}{l|cclll}
\hline $\begin{array}{l}\text { Implications } \\
\text { Exchange }\end{array}$ & Modularity & $\begin{array}{l}\text { Standard- } \\
\text { ization }\end{array}$ & $\begin{array}{l}\text { Source of } \\
\text { Competitive } \\
\text { Advantage }\end{array}$ & Main Benefit & $\begin{array}{l}\text { Competitive } \\
\text { Risks }\end{array}$ \\
\hline $\begin{array}{l}\text { Independent } \\
\text { e-Markets }\end{array}$ & Low & Low & No & $\begin{array}{l}\text { Improve market } \\
\text { competition and } \\
\text { transaction efficiency }\end{array}$ & None \\
\hline $\begin{array}{l}\text { Industry } \\
\text { Consortia }\end{array}$ & Medium & High & No & $\begin{array}{l}\text { Standardization } \\
\text { across industry }\end{array}$ & $\begin{array}{l}\text { Low, may promote } \\
\text { industry inertia }\end{array}$ \\
\hline $\begin{array}{l}\text { PrivateVertical } \\
\text { Exchanges }\end{array}$ & High & Medium & Yes & $\begin{array}{l}\text { Enable modular } \\
\text { supply chains }\end{array}$ & $\begin{array}{l}\text { Low, partners may } \\
\text { reject system changes }\end{array}$ \\
\hline
\end{tabular}

and organizational structures. In order to define the standardized interfaces required for a modular system, firms must transform this knowledge into an explicit form that can be used to develop network structures and computer software. This process has been described as one of "externalization." ${ }^{22}$ Externalization examines tacitly held shared understandings through a process of repeated dialogue. It uses trial-and-error tests of hypotheses and assumptions and techniques such as metaphor and analogy to tease out the causal linkages, implicit in the tacit knowledge and put them into an explicit form. Externalization is closely related to articulation and codification. Articulation also refers to the process of explicating the cause-effect linkages between actions and outcomes; codification takes this further by placing the articulated knowledge into a more rigorous framework (such as written manuals, computer systems, or blueprints). In doing so, it requires the exposure of underlying assumptions and the strict definition of logical connections. ${ }^{23}$

\section{The Impact of B2B Technologies on Supply Chains}

\section{The Role of Architectural Knowledge}

Exchange-enabled collaboration is a process based on harnessing B2B technology to facilitate increased modularity. Table 2 summarizes the benefits of common B2B initiatives. The patterns that emerge from this analysis are consistent with architectural knowledge playing a key role in establishing modular systems.

The tools currently supplied by independent e-marketplaces fall short of enabling modular systems. Most independent markets do not alter the information flows within a system or change the underlying superstructure associated with it. For instance, procurement has always entailed contracting with external parties, and the mere fact that this is done automatically via procedural rules built into a generalized electronic network rather than on a bilateral basis does not amount to a significant alteration. The limited nature of independent 


\section{Examples of Consortia-Fostered Collaboration}

Consortia aggregate and share the knowledge of their founding owners. This gives member firms a more complete view of their industry and its participants, and particularly of the architecture that is embedded within it. By making this information available, firms are better able to appreciate the knowledge structures operating around them, opening up the potential to modularize that architecture. Consortia are also developing tools to support collaboration. Aeroxchange (a consortia of 32 airlines, including Air Canada, America West, KLM, and Singapore Airlines-www.aeroxchange.com) is developing a tool to allow companies in the airline industry to disclose spare parts inventory information in real-time, minimizing the time and administrative costs required to find parts, while also opening up opportunities to share inventory. Inventory sharing will amount to a change in the way business is done, as it promises to systematically transform rivals from being a source of last resort to a more regular quasi-supplier. Similarly, Transora (www.transora.com), a consortium for the consumer packaged goods industry, is developing tools to solve the interlocking problems of planning, forecasting, and replenishment. Covisint has also made significant progress with tools that allow virtual teams to collaborate on product development, inventory visibility, and functionality allowing a firm to monitor quality throughout the supply chain. These tools allow firms to work together and to share decision making actively.

exchanges reflects their relative dearth of architectural knowledge. The majority of independent exchanges were established by start-up firms. These firms were able to adopt new B2B technologies quickly because they were unfettered by existing structures, routines, and processes. Ironically, these sources of organizational inertia are also critical sources of the architectural knowledge that is needed to alter the supply chain radically. Without extensive architectural knowledge, the codification and standardization that enable modular approaches are almost impossible to achieve.

Current consortia initiatives go further than those of independent e-marketplaces, often providing tools that allow firms to collaborate. The sidebar above outlines just a few examples of consortia B2B initiatives. The only significant disadvantage consortia face is that they generally have a narrower user base (of suppliers) than independent e-markets, because as they tend to favor the existing trading partners of their members. However, this actually supports the introduction of modular systems by making standardization simpler by narrowing the diversity of participants. More importantly, consortia also act as an institutional structure that can actively negotiate and champion communication standards, using their market power to encourage adoption. The B2B initiatives pursued by consortia are consistent with their architectural knowledge and clearly benefit from the accumulated experience of their members. However, competition between members also limits each consortium's access to proprietary knowledge. In some cases this can hamper collaborative initiatives. For instance, while DaimlerChrysler uses Covisint to access a wide selection of suppliers, it is also pursuing its own B2B initiatives, including an electronic sales service connecting dealers directly to factories. This reflects the need to 
differentiate offerings and protect proprietary knowledge in order to attempt to gain a competitive edge.

Private exchange initiatives are similar in scope to those of consortia. However, private exchanges are not as effective at promoting information sharing across industry participants. This is because private exchanges lack the broadly based market power that consortia use to promote the adoption of standards. Nevertheless, private exchanges do offer some additional benefits over consortia models. First, private exchanges give firms full discretion over the design and functionality of the exchange, allowing them to target specific areas where potential competitive advantages may arise. Further, these exchanges allow firms to actively manage risks by giving them control over the transactions of the exchange and what company information is disclosed to partners. These are advantages over the consortia model where this control is ceded to the exchange (in the faith that it will not be abused). ${ }^{24}$ However, perhaps the most significant advantage of private initiatives is that they allow firms to compete not only over the content of any single module, but over how their supply chains are arranged. For instance, the users of Covisint have the same collaborative opportunities, but DaimlerChrysler has the option of casting its chain in a different manner; indeed its e-business mission is to do just that and "make DaimlerChrysler the first networked automotive company across its entire value chain." ${ }^{25}$ That private exchanges go further is no surprise, as they have full access to the experience of their parent, providing deep architectural knowledge of the industry. Generally, private exchanges show the most promise for effective modularity because they possess similar characteristics to consortia approaches but with significant benefits in terms of focus, control, and competition.

\section{The Role of Supply Chain Indispensability}

Although this analysis suggests that organizations with high architectural knowledge can apply B2B technologies to implement modular systems, there are obvious differences in the form that these initiatives are taking. One key driver is how deeply embedded in the supply chain the activity is. ${ }^{26} \mathrm{~B} 2 \mathrm{~B}$ initiatives will look different depending on the role the focal firm plays in the supply chain, and how essential the firm's activities are to it. We define the degree of importance to the supply chain's activities as the firm's "supply chain indispensability." The degree of indispensability turns on the nature of the activity, including its capital intensity and scalability. The exchanges being developed by Eastman Chemical provide insight into these differences. Eastman, based in Tennessee, is a multinational chemical company employing over 15,000 people in more than 30 countries and possessing sales of $\$ 6.58$ billion in 2004 . It is a market leader in polyester plastics, coatings, and specialty chemicals. The chemical industry is marked by fluctuating demand as its main customers include the automobile, housing, and manufacturing sectors, each of which is characterized by highly cyclical, and at times volatile, demand. Moreover, Eastman faces inflexible production requirements, as the complexity of chemical processes often means that production cycles are several months long, and even when plants can switch 
production, there is often a sequence in which the different processes must be run in order to optimize production.

Eastman is adopting B2B technology to improve the utilization of its indispensable chemical production activities. These processes are very hard to supplant due to high fixed costs, the long lead-time required to build plants, and strict production sequences. Eastman is increasing information sharing by using B2B technology to connect its central enterprise resource planning (ERP) system to those of other firms in its supply chain. It has deployed integration servers provided by the specialist system integration software firm webMethods, to allow information to move directly between its internal systems and trading partners. Having access to information earlier gives Eastman better control over how it structures its business and allows it to draw on a wider range of suppliers in any given situation. Eastman is also continuing to lay the foundations for more extensive initiatives. For example, it is participating in the Chemical Industry Data Exchange (www.cidx.org), an industry association that seeks to establish XML standards to "[improve] the ease, speed, and cost of transacting business electronically between chemical companies and their trading partners." ${ }^{27}$ These standards promise to simplify the task of integrating systems across organizations - opening the way for further application of B2B technology. These B2B initiatives place primary emphasis on Eastman's existing capacity and how it can be utilized more effectively. They are targeted inwards and aim to improve the flexibility and performance of Eastman's internal supply chain activities.

Eastman also has several B2B initiatives that address dispensable activities. These include initiatives that are aimed at leveraging Eastman's knowledgebased activities, such as logistics coordination, and its wider understanding of the chemical market. First, it established Cendian (www.Cendian.com), a subsidiary that offers logistics coordination. Drawing on Eastman's expertise, Cendian can plan and optimize logistics for its clients, which include Eastman and its competitors. More importantly, because chemicals react with each other, it is important that transport sequences do not bring certain chemicals (and the residues they leave behind in containers) into contact with each other. Cendian is able to coordinate transport activities across firms and carriers to manage this need. It can also track shipments, chase problems, and has facilities to handle administrative tasks such as payments and customs requirements. Eastman also established PaintandCoatings.com (www.PaintandCoatings.com) a B2B exchange that allows customers to browse through an array of chemical alternatives and provides buyers with detailed information through access to a database on solvents. PaintandCoatings.com permitted Eastman's competitors to list their products, and included links to industry associations and events, providing channels for industry communication. Although a more limited initiative, PaintandCoatings.com provides a central point to bring together buyers and suppliers to improve matching. ${ }^{28}$ Both these initiatives reach out to new participants, drawing them together to facilitate new supply arrangements. 
FIGURE 2. Strategic Outcomes of B2B Technology

\section{Architectural Knowledge}

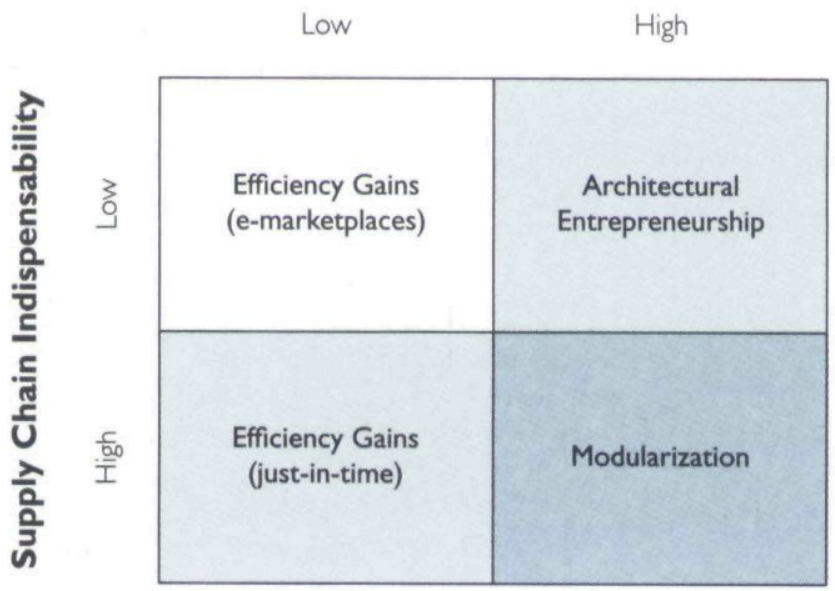

Eastman's application of B2B technology is pulling in two directions: streamlining internal operations and reaching out to new participants. These two directions, which are a result of applying B2B technology to indispensable and dispensable activities, suggest two distinct B2B strategies. We term the inward focused strategy "modularization" as it seeks to broaden the scope of application of an indispensable supply chain activity. The outward focused strategy is one of "architectural entrepreneurship" as the focal firm reaches out to coordinate participants into new supply chain arrangements. Figure 2 summarizes the framework and how architectural knowledge and supply chain indispensability influence the outcomes of the application of B2B technologies.

\section{Applying B2B Technology: The Two Modular Strategies}

Two companies, Cemex and Li \& Fung, have applied modular strategies extensively. By using modularity to break discrete components out of its supply chain and then renting these out to other firms, Cemex provides a powerful example of the modularization strategy. Although the content of the module is drawn from existing knowledge-in this case, Cemex's IT and construction management capabilities - the capabilities that support delivery in this form can be quite different. In moving to the delivery of construction and IT knowledge, Cemex had to learn how to interact with customers in a more complex way and relied heavily on the service capability it had developed through the operation of its cement delivery network. This presents a challenge to firms wanting to follow a model similar to Cemex's: without appropriate complementary capabilities, a module's value will be strictly limited. Indeed, firms will prefer to rely on their 
TABLE 3. Two Distinct B2B Strategies

\begin{tabular}{|c|c|c|}
\hline Strategy Attributes & Modularization & Architectural Entrepreneur \\
\hline Aim & $\begin{array}{l}\text { To utilize existing knowledge } \\
\text { resources over a wider domain }\end{array}$ & $\begin{array}{l}\text { To replace the "invisible hand" as the } \\
\text { market coordinator }\end{array}$ \\
\hline \multirow[t]{3}{*}{ Key Benefits } & \multirow{3}{*}{$\begin{array}{l}\text { - Knowledge becomes product } \\
\text { avoiding commoditization } \\
\text { - Low overhead reduces overall } \\
\text { capital intensity }\end{array}$} & - More efficient production \\
\hline & & - Better expectation fulfillment \\
\hline & & \\
\hline \multirow[t]{4}{*}{ Key Challenges } & \multirow{4}{*}{$\begin{array}{l}\text { - Adding sufficient service capability } \\
\text { - Take up: Encouraging adjacent } \\
\text { firms to adopt module }\end{array}$} & - Maintaining market power balance \\
\hline & & within the supply chain \\
\hline & & $\begin{array}{l}\text { - Avoiding dilution of firm's advantage } \\
\text { as knowledge leaks into infrastructure }\end{array}$ \\
\hline & & $\begin{array}{l}\text { - Take up: Encouraging adjacent firms } \\
\text { to accept entrepreneur role }\end{array}$ \\
\hline Risk & Low & Medium \\
\hline \multirow[t]{2}{*}{$\begin{array}{l}\text { Lessons for } \\
\text { Implementation }\end{array}$} & \multirow{2}{*}{$\begin{array}{l}\text { Modularized skill should be } \\
\text { provided through a subsidiary to } \\
\text { allow it to optimize its service } \\
\text { capability, and avoid damaging the } \\
\text { firm's own specialized culture. }\end{array}$} & $\begin{array}{l}\text { - Unless external system is open it } \\
\text { will be very hard to encourage } \\
\text { partners to connect }\end{array}$ \\
\hline & & $\begin{array}{l}\text { - Internal IT system must be } \\
\text { proprietary to protect knowledge }\end{array}$ \\
\hline
\end{tabular}

own limited knowledge rather than pay for bad service. Li \& Fung is using its architectural knowledge very differently: to change the architecture of the supply chain. This architectural entrepreneurship strategy draws upon the firm's architectural knowledge to cast the supply chain more efficiently than would be achieved through the price-driven market. By permeating all of the linkages within the network that forms the chain, Li \& Fung is able to improve information flows and co-ordinate transactions more efficiently than the 'invisible hand' of the price mechanism. Details of the two strategies are outlined in Table 3.

\section{The Modularization Strategy}

Cemex uses its architectural knowledge to draw out the capabilities found within the firm, distilling them into a module that can then be rented out to other parties. It has long possessed extensive construction and IT knowledge, developed to manage cement deliveries under the environmental pressure imposed by traffic in Mexico City, but B2B technology is allowing it to leverage these skills more widely. This is achieved through two discrete initiatives: using modularization of construction knowledge (through its subsidiary Arkio) to enable customers to work even more closely with Cemex; and the modularization of its own IT and management capabilities (through its Neoris subsidiary). Cemex is offering these capabilities as modules that customers can "integrate" 


\section{Cemex: Value Adding in Cement Production through Modularization}

Cemex is a highly successful cement company and has a history of excellent utilization of IT. With its base in Mexico, it has expanded to become a global player in cement, with extensive operations throughout world. Global sales were US\$7.8 billion in 2004. Cemex's subsidiary CxNetworks is pursuing several B2B initiatives including construction e-marketplaces, an eprocurement alliance, and a supply chain consultancy. Chairman and CEO Lorenzo Zambrano, in launching CxNetworks, described its aim as to "leverage Cemex's assets onto the Internet" and "become the leading provider of Internet-based business solutions for the construction industry"* The supply chain consulting business, called Neoris, is focused on optimizing a customer's supply chain by streamlining how they interact with their suppliers and partners. Juan Pablo San Agustin, CEO of CxNetworks, has noted that, in the opinion of senior management, the "deconstruction" of existing supply chains to compete on the basis of individual activities represented the future for "our" enterprises.**

Cemex's exchange initiatives fall into three major categories. First, construction vertical marketplaces run by CxNetworks' subsidiary Arkio (www.arkio.com) that facilitate online purchasing from extensive product catalogues, provide industry information and financial tools, as well as operating "work centers" that lower the cost of accessing the technology for small businesses - thereby leveraging Cemex's expertise across more customers. Second, building eprocurement marketplaces though Latinexus, an industry consortium of which Cemex was a founding member, which specialized in indirect goods (such as maintenance, repair, and operations supplies). Third, supply chain integration consultancy services delivered through the CxNetworks subsidiary Neoris (www.neoris.com), which was Cemex's former IT department.

Overall, the picture of Cemex that emerges is complex and dynamic. Although, traditional building material supply remains their core activity, Cemex is increasing the importance of its management, industrial, and IT knowledge to its ongoing performance. It is strategically directing itself away from the production of a commodity to value-adding using its knowledge resources.

*L. Zambrano "Serving Global Building Needs," (September 2000), available at <wuw.cxnetworks.com/op5_I.htm>.

***.P. San Agustin "CxNetworks," (March 200I), available at <umw.cxnetworks.com/op5_I.htm>

into their own supply chains. This modular "integration" is vastly different from traditional vertical integration. Although there is the formation of what seems, from the outside, to be a complex whole, the modules retain a distinctive independence, such that the integration is merely superficial.

Cemex is doing more than merely improving the operation of existing processes; rather, it is fundamentally changing its business model by packaging itself into easily accessible modules so that other parties can incorporate Cemex into their supply chains. These new supply systems provide a Schumpeterian gain, accrued by leveraging resources to produce Ricardian rents across a wider 
domain. However, this extension does not require the tight linkages of traditional vertical integration, where Cemex would have to use ownership to buy its way into those supply chains. Instead, technology enabled modularity allows the activity to remain independent and loosely coupled from the firm's other activities. Firms are then tightly bound to the interfaces that connect modules, rather than being bound directly to the adjacent modules themselves.

\section{The Architectural Entrepreneurship Strategy}

Li \& Fung uses its architectural knowledge to substitute an optimized superstructure for the embedded architecture that exists in its markets. This role has been described as being a network "orchestrator." ${ }^{29}$ However, this goes further than merely coordinating the network as Li \& Fung also adds important information and guarantees to the interactions between modules. One important advantage that an architectural entrepreneur like Li \& Fung offers over market coordination is that it can customize the supply chain to suit each retailer's individual needs. It is able to impose the optimal structure for each transaction, rather than allowing the market to provide the most efficient generic structure. Further, while markets reach an efficient aggregate equilibrium, this process takes time, and in the interim inefficiency can result. This is particularly important in industries where demand can change quickly, such as fashion, because these markets will often move out of equilibrium. Even when markets are out of equilibrium, Li \& Fung can adjust arrangements long before market forces stabilize.

Li \& Fung also uses its knowledge to orient and monitor the performance of many of the modules that it selects for the network. For instance, they use

\section{Li \& Fung: Operating a Modularized Trading Network}

Founded in 1906, Li \& Fung is a classical trading intermediary. It draws on its extensive local knowledge to assist foreign retailers to find manufacturers who can fulfill their specifications at minimal cost. Initially, its assistance was based on being able to translate languages between the parties and having a broad knowledge of the capabilities of local firms. Over time, this knowledge developed to the stage where Li \& Fung were able to coordinate the entire supply chain.

Li \& Fung's major role is to assess retailer needs and then assemble an optimal network composed of the several modules required to create these products. Victor Fung, the Chairman of $\mathrm{Li}$ \& Fung, notes that what the company does "is close to creating a customized value chain for each customer." ing." The company has taken this further by not only selecting modules to lower costs, but also to ensure quality and optimize all aspects of production. In doing this it is drawing on its architectural knowledge of how the process modules fit together. Li \& Fung's coordination allows it to arrange systems that would not be viable under normal market conditions.

*]. Magretta "Fast, Global, and Entrepreneurial: Supply Chain Management, Hong Kong Style," Harvard Business Review, 76/5 (September/October 1998): 102-114. 
their own inspectors to check the quality of intermediate products. This monitoring substitutes for direct trust between the parties, which is often absent because the systems are one-off compositions of parties that have never transacted together before. Reliance on trust would necessarily restrict parties to a much smaller pool of suppliers and customers. Further, Li \& Fung's deep architectural knowledge of the participating modules enables them to make allowances for firm idiosyncrasies. It uses this knowledge to improve matching by aligning expectations; understanding all the stages of production, it can reliably translate specifications between them. Importantly, Li \& Fung also prevents any of the firms in the supply chain from taking advantage of the other firms. For instance, a link in the supply chain may be subject to moral hazard or monopolistic tendencies, such as a small manufacturer cutting corners on production quality or where a large retailer might squeeze small suppliers using their buying power. Li \& Fung's coordination role prevents these problems from occurring, making the system viable by ensuring that the interfaces and interactions across them are sufficient and accurate. This facilitates the establishment of standardized processes, because the ability to intervene allows it to deploy standard processes across a broad range of situations.

Li \& Fung's central role allows it to add much value, but it also gives it considerable market power. As an opt-out system, the selected parties can only choose between accepting the offer to join the network being assembled for this order or rejecting it. Firms cannot participate in this supply chain without Li \& Fung's invitation and, consequently, do not have much power over how Li \& Fung decides to structure it. This creates the risk that Li \& Fung could extract rents from the modules it selects. To counter this problem Li \& Fung, somewhat counter-intuitively, requires that its partners work with its rivals to maintain balance in its own relationship with them, with Li \& Fung only constituting $30-70 \%$ of a client's sales. This ensures that suppliers are not dependent and hence vulnerable to Li \& Fung itself. This also explains why it has pursued an open system, rather than attempting to build proprietary network infrastructure. In contrast to its proprietary XTS 5 internal trading system, it has adopted Microsoft's BizTalk Server to connect to external parties. By adopting the infrastructure product of a neutral provider, Li \& Fung is able to customize superstructures without threatening the independence of their partners. So, while the addition of modules to each supply chain is under its control, and it receives Schumpeterian rents for designing these networks, firms still retain the capacity to transact with other parties, reducing the threat of hold-up.

Although necessary to maintain balance in its partner relationships, the splitting of superstructure from infrastructure creates a risk for Li \& Fung: it has no proprietary claim over the network, its position being maintained purely by the value that its specialized architectural knowledge adds. However, at the same time partners are accumulating this knowledge themselves through exposure to these transactions. This dilution of Li \& Fung's architectural knowledge creates the risk that the infrastructure may be able to operate without their input, as parties develop the knowledge necessary to establish networks themselves. This is exactly the problem that it faced in Hong Kong during the 1970s. Over time, 
margins were squeezed from $10 \%$ to $3 \%$ as trading partners developed the knowledge necessary to manage their own sourcing in Hong Kong. Li \& Fung responded by expanding their knowledge beyond the grasp of partners. The challenge for Li \& Fung is to continue to build its architectural knowledge, staying ahead of participants, such that it is able to structure more-effective supply chains than the firms it coordinates could using their own knowledge.

\section{Challenges for Start-up Firms: Agribuys and Architectural Knowledge}

Agribuys' B2B initiative offers a useful contrast to the cases examined above. It confirms the role of architectural knowledge. Founded in 1999, Agribuys is an independent e-marketplace that focuses on the fresh food industry, including, fruits, vegetables, meat, fish, and poultry. It does not trade on its own behalf; instead it facilitates trading in the sector by providing a system that supports transactions between the growers, suppliers, wholesalers, and retailers who make up the industry. Although Agribuys' espoused strategy is to adopt an architectural entrepreneurship strategy like Li \& Fung, they possess far less extensive architectural knowledge. Consistent with the theoretical propositions, their B2B initiatives are limited to developing systems that conform to the existing architectural arrangements.

Agribuys' initiatives do not enable modular arrangement or threaten to recast industry structures. Indeed, its success is based on adhering to existing structures. Agribuys' system is based around three software products: OrderLink, Delivery-Link, and Logistics-Link. Order-Link allows a buyer to aggregate their demand information and inform and negotiate with suppliers. The system can then execute and fulfill transaction processes. Delivery-Link enables a party to track goods from the supplier to their destination and to generate claims should there be any problems with the delivery. Logistics-Link coordinates logistics by streamlining the process of building compatible shipments of cargo that can then be assigned to carriers. Each of these components is designed to support the idiosyncrasies and specialist requirements of the fresh food industry, such as the need to refrigerate some cargo and the time sensitivity of delivery. All these transactions take much the same form as they do in an offline format.

Established relationships still dominate the fresh food industry, even for parties that use Agribuys' system. The importance of established relationships to these firms is itself a symptom of the inability to measure quality effectively. These relationships are developed through ongoing interactions and then used to ensure quality over repeated transactions. Agribuys has worked around this need, by establishing a system that supports both ongoing relationships and reputation building, while providing tools that can support the iterative communication needed to transfer accurate quality information. Unfortunately, this also means that Agribuys is restricted to capturing the efficiency gains that their management acknowledges are of relatively low value. 
Given this analysis, current B2B offerings in the fresh food industry may be seen as an intermediate development. One could envisage a more radical modular intermediary in the fresh food category. This hypothetical firm would place itself between buyers and sellers and be able to match orders with the correct supplier, allowing for both differing reputations and interpretations between the parties. Indeed, Agribuys is engaged in activities that suggest it is building towards more modular B2B initiatives. For instance, Agribuys has established an alliance with the World Wide Retail Exchange (WWRE)—a private consortium representing 64 leading retailers with combined sales of over US\$900 billion. WWRE offers procurement and some limited collaboration tools, but its most significant activity is in setting standards. WWRE is able to use its large size to push forward the standardization central to modular strategies. Agribuys is also able to lever off this connection to increase the adoption of its infrastructure. Interestingly, in contrast to Li \& Fung, Agribuys is able to run a proprietary network. Because it adheres to existing structures it does not control the ability of firms to participate, as they can implement the same processes through alternate means. This reduces the threat of hold-up, such that parties are willing to participate in a proprietary system. Meanwhile, during the course of their infrastructure provision, Agribuys is continuously building its architectural knowledge. This knowledge holds the key to implementing a more radical modular strategy. Indeed, its evolution from a sales-based to consulting-based business model suggests Agribuys is moving towards this goal. This recent change reflects a deepening of their knowledge, and the ongoing expansion of the role it is playing. If this continues, Agribuys may be able to enact its strategy and become an architectural entrepreneur, moving from providing supporting infrastructure to designing the superstructure of the market itself.

\section{Summary}

The two distinct strategies of modularization and architectural entrepreneurship clarify the strategic importance of B2B technology and why architectural knowledge is so critical to its successful implementation. Table 4 provides an overview of the four firms discussed and highlights their differences and similarities.

\section{Evolutionary Perspectives and Rent-Seeking}

There are two trends influencing the application of B2B technology. The first reflects the choices firms make to maximize rents, both Ricardian and Schumpeterian. The other is the evolution of industries and products. These two effects are closely intertwined, leading to a process of co-evolution between industries and firms. ${ }^{30}$

The evolution of industries tends to decrease the indispensability of supply chain activities. Over time, products and processes become increasingly better understood, as the technology supporting them becomes more and more widely available through the diffusion of knowledge and as regulatory 
TABLE 4. Summary of Case Study Firm Characteristics and their B2B Initiatives

\begin{tabular}{|c|c|c|c|c|}
\hline Attributes & CEMEX & Eastman & Li \& Fung & Agribuys \\
\hline $\begin{array}{l}\text { Architectural } \\
\text { Knowledge }\end{array}$ & Deep* & Deep & Deep & Shallow \\
\hline Strategic Goal & Become Module & $\begin{array}{l}\text { Become Module } \\
\text { and Superstructure }\end{array}$ & $\begin{array}{l}\text { Become } \\
\text { Superstructure }\end{array}$ & $\begin{array}{l}\text { Become } \\
\text { Infrastructure then } \\
\text { Superstructure }\end{array}$ \\
\hline $\begin{array}{l}\text { B2B Exchange } \\
\text { Initiative Risks }\end{array}$ & $\begin{array}{l}\text { Low (need to enable } \\
\text { partners to connect } \\
\text { to their interface) }\end{array}$ & $\begin{array}{l}\text { Low } \\
\text { (protected by own } \\
\text { capacity) }\end{array}$ & $\begin{array}{l}\text { Medium (possible } \\
\text { that architectural } \\
\text { knowledge leaks } \\
\text { into infrastructure) }\end{array}$ & $\begin{array}{l}\text { High (need to build } \\
\text { knowledge without } \\
\text { becoming threat to } \\
\text { partners) }\end{array}$ \\
\hline Market Role & Active Participant & Active Participant & Intermediary & Intermediary \\
\hline $\begin{array}{l}\text { Firm Product } \\
\text { Characteristic }\end{array}$ & Physical Commodity & Physical Commodity & Knowledge-Based & Knowledge-Based \\
\hline Industry & $\begin{array}{l}\text { Building Products } \\
\text { (Cement) }\end{array}$ & Chemicals & $\begin{array}{l}\text { Manufacturing } \\
\text { (Apparel and Home } \\
\text { Wares) }\end{array}$ & Fresh Food \\
\hline Industry Challenges & $\begin{array}{l}\text { Commoditization } \\
\text { of Product }\end{array}$ & $\begin{array}{l}\text { Inflexible } \\
\text { Production }\end{array}$ & $\begin{array}{l}\text { Consumer Tastes } \\
\text { Hard to Measure }\end{array}$ & $\begin{array}{l}\text { Difficulty Measuring } \\
\text { Quality. Food } \\
\text { Spoilage }\end{array}$ \\
\hline Capital Intensity & High & High & Low & Low \\
\hline Demand & Fluctuating & Fluctuating & Fluctuating & Stable \\
\hline Supply & Stable & Stable & Stable & Fluctuating \\
\hline Customer & End-User & $\begin{array}{l}\text { Intermediary/ } \\
\text { Retailer }\end{array}$ & Retailer & Retailer \\
\hline $\begin{array}{l}\text { Upstream } \\
\text { Trading Partners }\end{array}$ & Few Suppliers & Many Suppliers & Many Suppliers & Many Suppliers \\
\hline $\begin{array}{l}\text { Downstream } \\
\text { Trading Partners }\end{array}$ & Many Buyers & Many Buyers & Few Buyers & Few Buyers \\
\hline
\end{tabular}

* Shading draws attention to characteristics that correlate with the strategies being adopted by the firms.

protections such as patents expire. ${ }^{31}$ This increases the competitive intensity in industries as growth slows and firms become increasingly homogeneous. ${ }^{32}$ These pressures lead firms to drift upwards in the framework given in Figure 2-i.e., from being indispensable to dispensable-reducing their ability to extract Ricardian rents. This common occurrence is often described as product commoditization. There are several ways to respond to these pressures. The simplest is to invest in technologies that reduce costs. This invariably leads to trading off variable for fixed costs, as firms invest in more sophisticated technologies to 
maintain their cost advantage. Yet this is unlikely to be sustainable in the long run. The ongoing pressures faced by the semiconductor manufacturers, despite enormous capital investments, reflect this. In the B2B domain, initiatives such as just-in-time manufacturing and collaborative demand planning support this response. Another alternative is to innovate. Innovation, as noted, can address the substantive components of a product or their architectural arrangement. Component innovation reduces pressure by creating new knowledge that has not been diffused, allowing the firm to shelter from competitive forces. ${ }^{33}$ Modular strategies provide the third alternative, accepting the loss of Ricardian rents but seeking to shift the firm towards the right-hand side of our framework where they can collect Schumpeterian rents.

\section{Co-Evolution in the Computer Industry: Dell and Adaptive Strategies}

These trends suggest that as industries mature, firms are required to move beyond mere efficiency benefits and pursue modular strategies in order to continue to earn rents. This is apparent in the evolution of the computer manufacturing industry. Computer manufacturing has matured at a rapid rate, quickly eroding the indispensability of manufacturers and their ability to collect Ricardian rents. Pre-assembled computers based-on a number of competing designs started to appear in 1975. In 1981, IBM introduced its non-proprietary PC design, which quickly became the dominant standard, garnering $85 \%$ of the market by the mid-1990s. By this stage, a mere 20 years from the product's introduction, the industry was mature, and a new entrant could easily establish a generic plant for as little as \$1 million to assemble 250,000 computers per year. ${ }^{34}$ The extent of product commoditization was reflected by the share of unbranded "white box" sales, making up $23 \%$ of the market in the U.S. and $50 \%$ in Europe and Asia. ${ }^{35}$

A salient example of how B2B strategies can be used to manage rapid market evolution is the success of Dell Inc. Founded in 1984, Dell has become a global computer systems provider offering a broad array of computing products ranging from desktops, laptops, and handhelds to servers and network switches. By 2004, Dell's annual revenue had reached $\$ 41.4$ billion and the firm employed 53,000 people. Its enormous growth has been reflected by the appreciation of its stock price, with raw monthly returns averaging over $4.3 \%$ since its listing in 1988. This is despite the evolution of the computer industry placing significant pressure on firms, with several delivering large annual losses during the 1990s, including Dell. An investigation of the initiatives that Dell has used to compete in this challenging environment places a strong emphasis on architectural knowledge and the growing importance of modular strategies.

Dell's success in the face of a highly competitive and turbulent industry has been supported by its innovative application of B2B technologies. Initially these initiatives focused on supply chain efficiencies. Dell's "direct model" is built on the extensive adoption of B2B systems, linking it to both its customers and suppliers. The efficiency of its supply chain is reflected by the number of days of inventory that it holds. By 2003, its days of inventory were down to 3 , 
from 55 in the early 1990s; this compared to roughly 20 days for its competitors. With component prices falling $1 \%$ per week, this translated directly into an objective cost advantage. ${ }^{36}$ However, rival firms have been able to adopt similar initiatives, overcoming Dell's advantage. For instance, IBM adopted an Authorized Assembly Program (APP) to improve its supply chain efficiency. The APP shifts the final stages of production to channel partners, who are better able to respond to customer needs. Compaq adopted a similar approach with its Optimized Distribution Model. In this way, competitors increasingly imitated supply chain aspects of Dell's direct model as it became clear that the previous supply chain structure was unsustainable. In order to maintain its position, Dell also established several B2B exchanges. In 1999, it launched Gigabuys.com, an online store that consumers could use to purchase almost anything associated with computers, from routers and network cards to software and digital cameras. In 2000, it also established a B2B e-Marketplace based on Ariba Inc's IBX software. This B2B exchange promised access to a broad range of customers delivering benefits in terms of improved matching and low cost electronic procurement.

However, the confluence of competitor imitation and industry evolution has rendered these efficiency-driven initiatives insufficient to support superior performance. More specifically, Figure 3 shows the monthly stock returns associated with efficiency-based B2B initiatives and compares these with modular initiatives. The event entries were collected by a review of Dell's archive of media announcements ${ }^{37}$ and searches of major U.S. publications in the Factiva news database. Dell's monthly stock returns are adjusted relative to the NASDAQ Computer Index. Interestingly, although the earliest efficiency initiative, the adoption of online sales, resulted in positive returns, these types of initiatives soon lost market favor. Indeed, the mean adjusted market return in months in which efficiency-driven initiatives were made public was $-3.57 \%$. It is no surprise that in this environment Dell subsequently closed its B2B e-marketplace, citing a lack of customer interest. In the face of eroding efficiency advantages, Dell's application of B2B technologies has become increasingly modular. This has enabled it to shift towards the right of the framework, pursuing Schumpeterian rents. This adoption of modular strategies has been facilitated by Dell's extensive architectural knowledge.

Dell's direct model has played an important role in providing the rich architectural knowledge that supports modular strategies. Critically, the exposure to customers entailed by the company's direct approach has provided a broad scope for experience accumulation and also allowed the development of a deeper understanding of customer needs than many of its rivals. ${ }^{38}$ Interestingly, although other firms play more extensive roles in other areas, such as HewlettPackard's involvement in R\&D and design, this exposure has not provided a source of advantage in applying B2B technologies to customer needs. This is consistent with the role of computer design standards, first established by IBM, which set out the basic architecture of computer systems and marginalize many of the insights that design capabilities could produce. This "Wintel" standard is 
FIGURE 3. Dell Monthly Return (adjusted for NASDAQ Computer Index) and Modular Initiatives

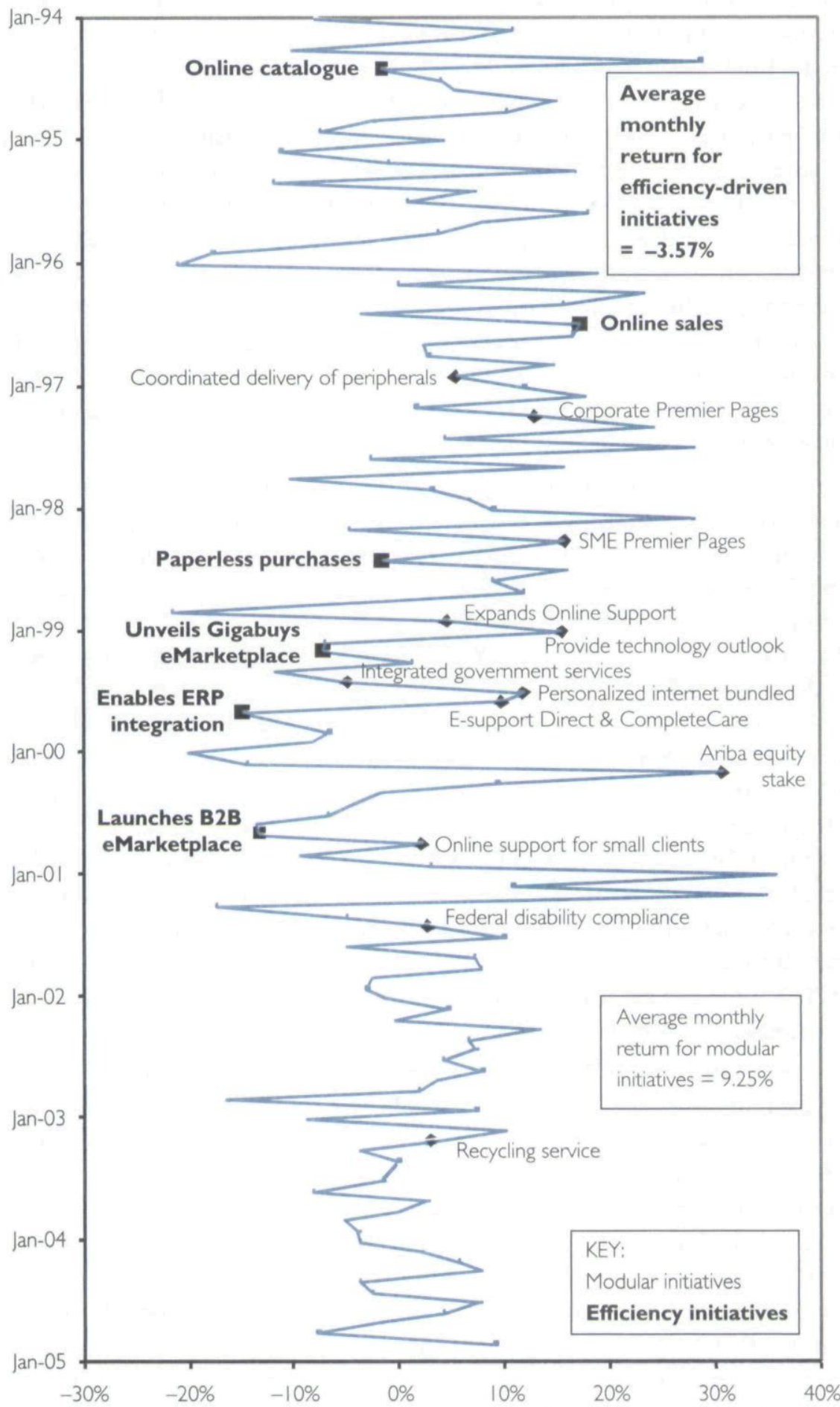


built around Intel's chipsets and their Instruction Set Architecture, and Microsoft's Windows software protocols including Application Programming Interfaces and file formats (as supported by strong network externalities). By setting the relationships between system components, these standards have reduced the importance of design capabilities, restricting their competitive value to internally altering components. In a sense, the standards in the computer industry have prevented firms from differentiating themselves based on the product architecture, leaving the way for firms, such as Dell, to distinguish themselves by altering the architecture of business processes. By harnessing architectural knowledge, Dell's more recent B2B initiatives have concentrated on the modularization of its hardware management capabilities and fine-tuning its coordination role.

On the customer-side, Dell is providing tools that customers can embed into their own supply chains. It initially commenced online sales in 1996, allowing customers to access information and to make and track orders over the Internet. Tailored Premier Pages for business and institutional customers soon followed. These went beyond efficiency enhancing online ordering and allowed customers to manage their hardware needs by integrating their own corporate policies into Dell's ordering system. This is part of a larger B2B initiative that aims to package standardized services for customers. Neil Hand, a director of Dell's worldwide enterprise team, describes the company's recent moves as "looking for the common denominators that all customers need, so we can wrap standard professional services around those in a pre-packaged but flexible way." ${ }^{39}$ As part of this strategy, Dell also offers to pre-load customized software and does inventory tagging for customers. It has also expanded Premier Pages by integrating online B2B services that automate system maintenance. The OpenManage Resolution Assistant software automatically detects problems and automates client response policies. The HelpTech offering also makes the company's own troubleshooting tools and applications, formerly employed by Dell's support staff, available to customers directly. Dell's ImageWatch service provides customers with advanced knowledge of upcoming technological developments (subject to a confidentiality agreement). In these ways, it is modularizing its capabilities and integrating them into their customers' supply chains, in the process taking over functions formerly managed by internal IT departments. It has also begun to integrate other services such as regulatory compliance and recycling into its product offerings, expanding its role. For instance, it has established online support for the 1998 amendments to the federal Rehabilitation Act of 1973, Section $508 .{ }^{40}$ This provides advice and compliance assured bundles for government customers. Dell also offers to coordinate disposal and value recovery for its clients. These offerings are supported by B2B technologies that make them instantly and continuously accessible to clients. These initiatives provide customers with modularized value-added services that they can easily build into their computer-related activities.

On the supplier side, Dell has taken on more of a coordination role. Providers of stand-alone components increasingly deliver them directly to 
customers, bypassing Dell completely. For instance, monitors or peripherals go directly to the customer, bundled with the other components by the 3rd party logistics provider prior to delivery. This decreases the emphasis on the company's traditional assembly role, making it more an architectural entrepreneur that draws together coalitions of firms to serve customer needs better. The shift in this direction was supported by also taking an equity investment in Ariba, the B2B software firm, providing closer access to capabilities built around understanding business processes and the relationships that frame them. However, the most far-reaching development is Dell's expansion into other products, such as printers and consumer electronics. It has partnered with firms including Lexmark, Samsung, Fuji Xerox, and Kodak to access high-quality component knowledge in order to produce its own branded products. Here, Dell is acting in an entrepreneurial role, bringing together new coalitions of technological knowledge, manufacturing, and delivery capabilities. For instance, the entry into printing has put it into direct competition with Hewlett-Packard, the leader in the category. Despite having relatively weak R\&D capabilities of its own, Dell is relying on its richer knowledge of customers to coordinate the delivery of products that better serve their needs. This pits its command of the architecture of the customer side of the computer business directly against Hewlett-Packard's technological knowledge, betting that, in the words of Michael Dell, "the days of engineering-led technology companies are coming to an end." ${ }^{41}$ Dell is becoming an architectural entrepreneur, applying its understanding of customer needs to bring together new combinations of skills and resources to serve them more effectively.

The announcement of these modular initiatives was strongly associated with positive stock returns. The industry adjusted mean monthly return for modular initiatives was $9.25 \%$; this compared positively with the overall industry-adjusted mean return for Dell of $3.04 \%$ over all months in the entire period since the end of $1993 .{ }^{42}$ An analysis of variance confirmed that this difference was statistically significant ( $\mathrm{p}<0.05$ two tailed). Moreover, the market reaction to modular initiatives was significantly different from that to the efficiency gain events $(\mathrm{p}=0.021)$; with a mean difference between them of $12.82 \%$. This data supports the value of modular strategies and shows that they provide a strong response in situations where efficiency gains have become a mere table stake.

Figure 4 summarizes the positions of the firms we have examined. They reflect the two modular strategies and the diversity of architectural knowledge. The examination of Dell is instructive, as it illustrates how industry evolution makes firms increasingly dispensable; but that the ongoing acquisition of architectural knowledge-and its application in the form of B2B technologies that pursue modular strategies - can maintain the capacity to earn organizational rents. 
FIGURE 4. B2B Initiatives: Agribuys, Cemex, Dell, and Li \& Fung

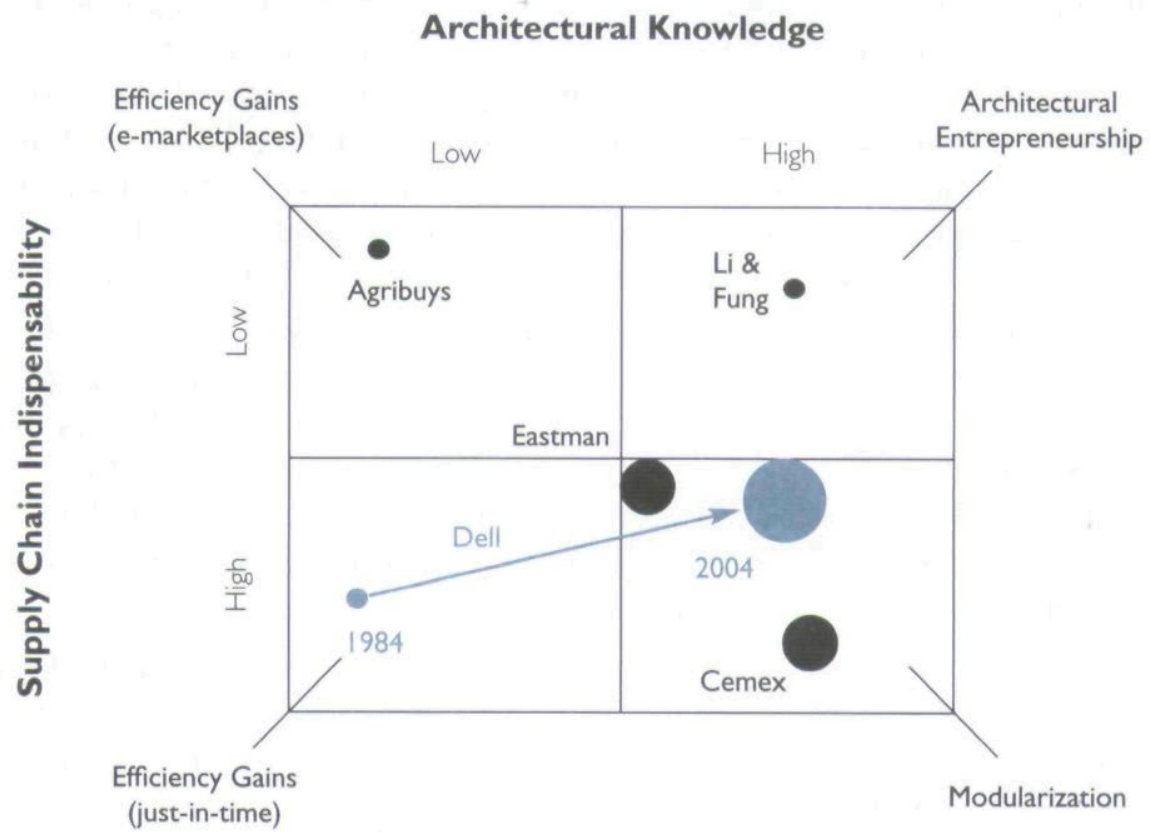

\section{Findings and Conclusions}

The references to "collaboration" in the literature on B2B technology reflect the underlying modularity of these initiatives. However, the terms "collaboration" and "integration" do not capture the reality of exchange operation, and their application to B2B initiatives borders on paradox. B2B technology adds value by decoupling tight internal connections and replacing them with modular interfaces. Parties then operate within the structure set out by the interfaces. Thereafter, the interaction between parties is intermediated by the interface and a better term to capture phenomenon is "distant collaboration," an expression reflecting the fact that although the parties are working together, they are doing so in a relationship that is externalized. Integration is even less appropriate. Though the supply chain operates as a seamless whole, it is actually composed of standardized interfaces that form strong boundaries between the firms. Thus, in actuality, the structure is decoupled and only loosely integrated. The value of modular systems is that they make full vertical integration unnecessary, because distant collaboration is able to operate in its place. Standardization is the cornerstone of B2B initiatives. Standardization makes the tight bonds of traditional vertical integration unnecessary, because it removes the potential for opportunism to hamper production and overcomes the risk of hold-up by enabling parties to switch between different partners easily and cheaply. ${ }^{43}$

The ability of firms to enact modular strategies is dependent on their architectural knowledge. Li \& Fung has successfully adopted such a strategy, 
but only because of its extensive architectural knowledge. The Agribuys case supported this finding, by illustrating how shallow architectural knowledge could severely curtail the application of B2B initiatives, limiting Agribuys to infrastructure provision. This lack of specialized architectural knowledge explains why so many independent e-marketplace start-ups failed. Consistent with this explanation is recent evidence suggesting that the proportion of independent start-ups that ceased operations was statistically greater than the proportion of incumbent linked exchanges that closed. ${ }^{44}$ This suggests that firms should treat the acquisition of architectural knowledge as a strategic activity.

The form that B2B initiatives take depends critically on the indispensability of that firm to the supply chain. Firms that have an active role and whose position is protected by cost advantages and high fixed costs should adopt modularization strategies, leveraging their capabilities more widely to earn Ricardian rents in these new areas. Those that fulfill scalable coordination roles should pursue architectural entrepreneurship strategies-bringing together new coalitions of firms to generate Schumpeterian rents.

The ongoing evolution of industries erodes firm advantages. Evolution places particular pressure on Ricardian rents, as firms reach the limits of their productivity frontiers and as products become increasingly commoditized through the diffusion of knowledge. However, the strategic application of modular strategies-in the form of technology-driven B2B initiatives-provides the opportunity to generate new Schumpeterian rents that can replace those that are eroded away. Architectural knowledge is crucial to this strategic response, making its accumulation and management more than a supporting activity, but rather a strategic priority.

\section{Notes}

1. T. Coltman, T.M. Devinney, A. Latukefu, and D.F. Midgley, “E-Business: Revolution, Evolution, or Hype?" California Management Review, 44/1 (Fall 2001): 57-86.

2. R. Sanchez and J.T. Mahoney, "Modularity, Flexibility, and Knowledge Management in Product and Organizational Design," Strategic Management Journal, 17 (1996): 63-76; M. Schilling, "Toward a General Modular Systems Theory and Its Application to Interfirm Product Modularity," Academy of Management Review, $25 / 2$ (2000): 312-334.

3. S. Jap and J. Mohr, "Leveraging Internet Technologies in B2B Relationships," California Management Review, 44/4 (Summer 2002): 24-38.

4. J. Westland and T. Clark, Global Electronic Commerce: Theory and Case Studies (Cambridge MA: MIT Press, 1999).

5. This is a situation further complicated by strategic alliances between exchanges. For instance, one of the cases discussed here considers the independent e-marketplace Agribuys. It has entered into an alliance with the WorldWide Retail Exchange (WWRE) consortium creating hybrid characteristics.

6. FreeMarkets merged with B2B software provider Ariba Inc. in 2004.

7. A. Afuah, "Redefining Firm Boundaries in the Face of the Internet: Are Firms Really Shrinking?" Academy of Management Review, 28/1 (2003): 34-53.

8. Sanchez and Mahoney, op. cit.

9. D. Galunic and K. Eisenhardt, "Architectural Innovation and Modular Corporate Forms," Academy of Management Journal 44/6 (2001): 1229-1249; M. Schilling and K. Steensma, "The Use of Modular Organizational Forms: An Industry Level Analysis," Academy of Management Journal, 44/6 (2001): 1149-1168; Schilling, op. cit.

10. Sanchez and Mahoney, op. cit. 
11. C.Y. Baldwin and K. Clark, "Managing in the Age of Modularity," Harvard Business Review, 75/5 (1997): 84-93; R. Sanchez, "Strategic Flexibility in Product Competition," Strategic Management Journal, 16 (1995): 135-159.

12. C.Y. Baldwin and K. Clark, "The Option Value of Modularity in Design: An Example from Design Rules, Volume 1: The Power of Modularity," Harvard NOM Working Paper No. 02-13, Harvard Business School Working Paper No. 02-078, <ssrn.com/abstract=312404> (2002).

13. O. Williamson, The Mechanisms of Governance (New York, NY: Oxford University Press, 1996).

14. Together one-to-one functional mapping and decoupled component interfaces are two hallmarks of modularity, see K. Ulrich, "The Role of Product Architecture in the Manufacturing Firm," Research Policy, 24 (1995): 419-440.

15. Ibid.

16. R. Henderson and K. Clark, "Architectural Innovation: The Reconfiguration of Existing Product Technologies and the Failure of Established Firms," Administrative Science Quarterly, 35/1 (1990): 9-30.

17. Ibid.

18. R. Rumelt, "The Many Faces of Honda," California Management Review, 38/4 (Summer 1996): 103-111.

19. L. Fleming and O. Sorenson, "The Dangers of Modularity," Harvard Business Review, 79/8 (2001): 20-21.

20. G. Gavetti, and D.E. Levinthal, "Looking Forward and Looking Backward: Cognitive and Experiential Search," Administrative Science Quarterly, 45 (March 2000): 113-137.

21. M. Zollo and S. Winter, "Deliberate Learning and the Evolution of Dynamic Capabilities," Organization Science, 13/3 (2002): 339-351.

22. I. Nonaka, "A Dynamic Theory of Organizational Knowledge Creation," Organization Science, 5/1 (1994): 14-37.

23. Zollo and Winter, op. cit.

24. The separation of exchange ownership (and control over design) from transaction participation has important implications for the ability to enforce the exchange's system on users. Obviously, private exchanges can force customers to use its system by having the owner commit to only transacting through that method. Consortia can also force adoption, but this is more indirect as control is intermediated by the consortia entity. Independent exchanges cannot use this leverage, as they do not participate in transactions that they can dedicate to this channel.

25. DaimlerChrysler web site, available at <www.dcx.net/mission/mission_e.htm $>$, last accessed September 11, 2002.

26. Supply chain indispensability is distinct from asset specificity as developed in transaction cost economics. Supply chain indispensability looks not at the appropriation of rents, but rather at their generation. Modular approaches would seem to reduce asset specificity, though that has not been addressed here. For a more detailed discussion on assets specificity, see O. Williamson, "Comparative Economic Organization: The Analysis of Discrete Structural Alternatives," Administrative Science Quarterly, 36 (1991): 269-296.

27. See Chemical Industry Data Exchange mission statement available at $<w w w . c i d x . o r g / A b o u t-$ CIDX/Mission.asp?Level=2\&SecondLevelURL1 =/AboutCIDX/AboutCIDX.asp $>$, last accessed September 24, 2003.

28. On July 1, 2004, Eastman announced that it had divested PaintandCoatings.com to SpecialChem, a broader independent e-marketplace operating in the specialty chemicals sector. Available at <www.eastman.com/News_Archive/Corporate_News/2004/040701.htm>, last accessed December 3, 2004

29. J. Hagel, "Leveraged Growth: Expanding Sales Without Sacrificing Profits," Harvard Business Review, 80/10 (2002): 69.

30. C.E. Helfat and R.S. Raubitschek, "Product Sequencing: Co-Evolution of Knowledge, Capabilities, and Products," Strategic Management Journal, 21/10 (2000): 961-979.

31. J.M. Utterback and W. Abernathy, "A Dynamic Model of Process and Product Innovation," Omega, 33 (1975): 639-656; D.J. Teece "Profiting from Technological Innovation," Research Policy, $15 / 6$ (1986): 285-305.

32. P.J. DiMaggio and W.W Powell, "The Iron Cage Revisited-Institutional Isomorphism and Collective Rationality in Organizational Fields," American Sociological Review, 48/2 (1983): 147-160.

33. K.B. Clark, "The Interaction of Design Hierarchies and Market Concepts in Technological Evolution," Research Policy, 14 (1985): 235-251; M.H. Boisot, "Is Your Firm a Creative 
Destroyer? Competitive Learning and Knowledge Flows in the Technological Strategies of Firms," Research Policy, 24 (1995): 489-506.

34. D.B. Yoffie, "Apple Computer 1992," Harvard Business School Case 9-792-081 (1994).

35. J.W. Rivkin and M.E. Porter, "Matching Dell," Harvard Business School Case 9-799-158 (1999).

36. Ibid.

37. Available at <wwwl.us.dell.com/content/topics/global.aspx/corp/pressoffice/en/index $>$, last accessed August 2, 2005.

38. Zollo and Winter, op. cit.

39. Quoted in J. Schofield, "Installation with that?" The Guardian, June 17, 2004, p. 16.

40. As amended by 29 U.S.C. § 794 (d).

41. Quoted in S. Lohr, "The Distributor vs. the Innovator," The New York Times, May 24, 2004, p. 1.

42. The NASDAQ Computer Index was judged as the most appropriate index to use to remove market noise. These results are based an analysis of Dell's monthly return from December 31, 1993 to December 31, 2004, as this index was only started at the end of 1993.

43. In transaction cost terminology this amounts to a reduction in the asset specificity of the module in question. See Williamson (1991), op. cit.

44. This research found a statistical significance of $p=0.06$, G.S. Day, A.J. Fein, and G. Ruppersberger, "Shakeouts in Digital Markets: Lessons from B2B Exchanges," California Management Review, 45/2 (Winter 2003): 131-150. 
Copyright of California Management Review is the property of California Management Review and its content may not be copied or emailed to multiple sites or posted to a listserv without the copyright holder's express written permission. However, users may print, download, or email articles for individual use. 